RUTMech, t. XXXVI, z. 91 (1-2/19), styczeń-czerwiec 2019, s. 5-16

Wiesław FRACZ1

Grzegorz JANOWSKI ${ }^{2}$

\title{
OCENA WPEYWU WYBORU MODELU MIKROMECHANICZNEGO NA PROGNOZOWANIE ORIENTACJI WŁÓKIEN ORAZ WŁAŚCIWOŚCI MECHANICZNE KOMPOZYTU WPC
}

\begin{abstract}
W pracy oceniono efektywność zastosowania modeli mikromechanicznych Folgara-Tuckera oraz RSC w prognozowaniu powtryskowej orientacji włókien w matrycy polimerowej dla specyficznego kompozytu WPC złożonego z matrycy polimerowej PP oraz napełniacza, tj. włókien drzewnych w ilości 15\% mas. Obliczone wartości składowych tensora orientacji włókien w matrycy polimerowej pozwoliły również na ocenę wpływu zastosowanych modeli mikromechanicznych na możliwości prognozowania właściwości mechanicznych kompozytu WPC z zastosowaniem modelu homogenizacji Mori-Tanaka. Należy zauważyć, że domyślnym modelem mikromechanicznym stosowanym $w$ wielu programach CAE specjalizowanych w zakresie procesu formowania wtryskowego jest model Folgara-Tuckera. Istotna staje się więc ocena przydatności modelu RSC, który nie jest modelem domyślnym i próba odpowiedzi, czy można go stosować w prognozowaniu właściwości przetwórczych i mechanicznych kompozytów WPC.
\end{abstract}

Słowa kluczowe: kompozyty, WPC, orientacja włókien, modele mikromechaniczne, formowanie wtryskowe, modele homogenizacji

\section{Wprowadzenie}

Głównym czynnikiem skłaniającym do stosowania włókien naturalnych w kompozytach polimerowych jest redukcja problemu zagospodarowania odpadów z tworzyw sztucznych. W latach 90 . XX w. rozpoczęto badania dotyczące wzmacniania polimerów naturalnymi napełniaczami, takimi jak np. włókna drzewne, dające grupę kompozytów WPC (ang. Wood Polymer Composites) [1]. O rozwoju możliwości stosowania tego typu napełniaczy zadecydowała ich dostępność, niska cena wytworzenia, satysfakcjonujące właściwości mechaniczne oraz biodegradowalność. Poprzez dodanie włókien pochodzenia roślinnego do matrycy polimerowej można się również spodziewać polepszenia właściwości

\footnotetext{
${ }^{1}$ Wiesław Frącz, Politechnika Rzeszowska, e-mail: wf@ prz.edu.pl

2 Autor do korespondencji/corresponding author: Grzegorz Janowski, Politechnika Rzeszowska, al. Powstańców Warszawy 8, 35-959 Rzeszów, tel. 17 8651714, e-mail: gjan @ prz.edu.pl
} 
mechanicznych wytworów wtryskowych. Kompozyty polimerowe z napełniaczami w formie włókien są więc materiałami perspektywicznymi, które mogą znaleźć zastosowanie w wielu gałęziach przemysłu [1-4].

$\mathrm{Z}$ uwagi na często znikome informacje dostępne na temat właściwości danego kompozytu należy skorzystać z nowoczesnych metod prognozowania, takich jak symulacje przetwarzania materiału kompozytowego, jak również przewidywania jego właściwości z użyciem modeli homogenizacji. Oba te kierunki badań symulacyjnych są ściśle związane z modelami mikromechanicznymi opisującymi orientację włókien w matrycy polimerowej oraz heterogeniczną strukturę kompozytu [5, 6].

Właściwości mechaniczne kompozytu polimerowego napełnionego włóknami zależą m.in. od przestrzennego rozmieszczenia włókien w matrycy polimerowej. Właściwa orientacja włókien w matrycy polimerowej w kierunku działania obciążenia może skutkować polepszeniem właściwości mechanicznych, jak również zwiększeniem gęstości oraz struktury geometrycznej powierzchni wypraski. Wśród napełniaczy włóknistych istotne znaczenie ma zastosowanie krótkich włókien o określonym stosunku długości do średnicy $(l / d)[1,7,8]$.

Rzeczywisty, przestrzenny opis powtryskowej orientacji włókien w matrycy polimerowej opisuje tensor drugiego rzędu. Tensor ten jest definiowany przez dziewięć składowych, zgodnie z kierunkami: wzdłuż przepływu tworzywa, poprzecznie do kierunku przepływu oraz na kierunku grubości gniazda formującego [9-12]:

$$
a_{i j}=\left(\begin{array}{lll}
a_{11} & a_{12} & a_{13} \\
a_{21} & a_{22} & a_{23} \\
a_{31} & a_{32} & a_{33}
\end{array}\right)
$$

Dość często składowe tensora mogą zostać uproszczone do mniejszej liczby. Wynika to z występowania symetrii $a_{i j}=a_{j i}$, jak również z warunku normalizacji: $a_{11}+a_{22}+a_{33}=1$. W konsekwencji można więc zdefiniować trzy główne składowe tensora orientacji włókien:

- $a_{11}$ - orientacja włókna wzdłuż kierunku przepływu (wartości z zakresu: $0-1)$,

- $a_{22}$ - orientacja włókna prostopadła do kierunku przepływu (wartości z zakresu: 0-1),

- $a_{33}$ - orientacja włókna na grubości kompozytu (wartości z zakresu: $-0,5-0,5)$.

Włókna rozmieszczone w osnowie polimerowej mogą być interpretowane jako wtrącenia zawieszone w lepkim medium, między którymi zachodzi interakcja hydrodynamiczna oraz mechaniczna. Zawiesina ta może być interpretowana (biorąc pod uwagę parametry włókna, takie jak: długość $-l$, średnica $-d$, stosunek 
długości do średnicy - l/d oraz objętościowy udział włókien $-c$ ) w trzech odmianach:

- stężona zawiesina, w której orientacja włókien jest skomplikowana z uwagi na uwzględnienie oddziaływań mechanicznych i hydrodynamicznych $(c>d / l)$,

- zawiesina średnioskoncentrowana, w której występują oddziaływania hydrodynamiczne, natomiast brak jest oddziaływań mechanicznych $((d / l) 2<c<(d / l))$

- zawiesina rozcieńczona, w której nie występują żadne formy oddziaływań $(c>d / l)$.

Biorąc pod uwagę komercyjne stosowane w przemyśle zawartości oraz parametry fizyczne napełniaczy, można założyć, że kompozyty polimerowe $\mathrm{z}$ napełniaczem mogą być traktowane jako średnioskoncentrowane lub najbardziej powszechne - stężone zawiesiny $[9,10]$.

Orientację włókien w stężonych zawiesinach można opisać z użyciem modelu Folgara-Tuckera [13]. Model ten opiera się na definicji tzw. bezwymiarowego współczynnika interakcji $c_{i}$ dla następujących założeń: występuje interakcja między włóknami z losową orientacją, oddziaływania włókien w kompozycie mogą występować, gdy zawiesina jest odkształcalna. Model Folgara-Tuckera ma postać:

$$
\frac{D a_{i j}}{d t}=-\frac{1}{2}\left(\omega_{i k} a_{k j}-a_{i k} \omega_{k j}\right)+\frac{1}{2} \dot{\lambda}\left(\dot{\varepsilon}_{i k} a_{k j}+a_{i k} \dot{\varepsilon}_{k j}-2 a_{i j k \varepsilon_{k l}}\right)+2 c_{i} \dot{\varepsilon}\left(\delta_{i j}-3 a_{i j}\right)
$$

gdzie: $c_{i}$ - współczynnik interakcji - parametr skalarny, którego wartość jest określona przez dopasowanie do wyników doświadczalnych,

$\omega .$. - tensor wirowości (.. - oznaczają wartości składowych tensora),

$\dot{\lambda}$ - stała zależna od geometrii cząstki,

$\delta_{i j}$ - składowa tensora,

$\dot{\varepsilon}-$ tensor szybkości odkształcenia,

$a \ldots$. - tensor orientacji włókien czwartego rzędu (....- oznaczają wartości składowych tensora),

a.. - tensor orientacji włókien drugiego rzędu (.. - oznaczają wartości składowych tensora).

Wspomniany model orientacji włókien jest powszechnie stosowany w obliczeniach orientacji włókien, w analizach numerycznych procesu formowania wtryskowego kompozytów polimerowych z napełniaczami włóknistymi. Ostatnie prace naukowe wskazują jednak, że model Folgara-Tuckera często daje przeszacowane wyniki orientacji wtrąceń w stężonych zawiesinach. 
W celu uchwycenia powolnej dynamiki zmiany orientacji włókien opracowany został model skorygowany, tj. RSC (ang. Reduced Strain Closure). Model ten w swoim założeniu opiera się na redukcji prędkości wzrostu wartości własnych tensora orientacji włókien przez współczynniki skalarne, nie zmieniając wartości wektorów obrotu. W odniesieniu do modelu Folgara-Tuckera został on zapisany w następującej postaci [14-17]:

$$
\begin{aligned}
& \frac{D a_{i j}}{D t}=-\frac{1}{2}\left(\omega_{i k} a_{k j}-a_{i k} \omega_{k j}\right)+ \\
& +\frac{1}{2} \dot{\lambda}\left(\dot{\varepsilon}_{i k} a_{k j}+a_{i k} \dot{\varepsilon}_{k j}-2\left[a_{i j k l \dot{\varepsilon}_{k l}}+(1-\kappa)\left(L_{i j k l}-M_{i j m n} a_{m n k l}\right)\right] \dot{\varepsilon}_{k l}\right)+2 \kappa c_{i} \dot{\varepsilon}\left(\delta_{i j}-3 a_{i j}\right)
\end{aligned}
$$

We wspomnianym modelu, w porównaniu z klasycznym modelem Folgara-Tuckera, parametr dyfuzyjny jest zredukowany o współczynnik skalarny $\kappa$, natomiast tensor czwartego rzędu $a_{i j k l}$ jest zastąpiony wyrażeniem:

$$
\left[a_{i j k l}+(1-\kappa)\left(L_{i j k l}-M_{i j m n} a_{m n k l}\right)\right]
$$

Z kolei tensory czwartego rzędu $M_{i j m n}$ oraz $L_{i j k l}$ są definiowane następująco:

$$
\begin{aligned}
& L_{i j k l}=\sum_{p=1}^{3} \sigma_{p} e_{i}^{p} e_{j}^{p} e_{k}^{p} e_{l}^{p} \\
& M_{i j m n}=\sum_{p=1}^{3} \sigma_{p} e_{i}^{p} e_{j}^{p} e_{k}^{p} e_{l}^{p}
\end{aligned}
$$

gdzie: $\sigma_{p}-p$-ta wartość własna tensora orientacji $a_{i j}$,

$e_{i}^{p}-i$-ty parametr $p$-tej wartości własnej orientacji tensora $a_{i j}$.

Model RSC może być użyty do uchwycenia powolnej dynamiki orientacji włókien, gdy współczynnik skalarny $\kappa<=1$. Im mniejsza jest wartość współczynnika skalarnego, tym wolniej wartość tensora orientacji zmienia się wraz z przepływem tworzywa i powstaje grubsza warstwa rdzenia. Z kolei model RSC jest zredukowany do standardowego modelu Folgara-Tuckera, gdy $\kappa=1[18,19]$.

Niejednorodna budowa kompozytów polimerowych często stanowi problem na płaszczyznach: przetwórczej, konstrukcyjnej oraz obliczeniowej. Modelowanie mikromechaniczne oparte na modelach homogenizacji daje możliwość prognozowania interakcji pomiędzy makro- oraz mikrostrukturą badanych kompozytów. W modelowaniu mikromechanicznym obszar materiału poddawany homogenizacji jest określany jako reprezentatywny element objętościowy (ang. Representative Volume Element - RVE). RVE powinien spełniać zasadniczy 
warunek - musi zawierać wtrącenie oraz osnowę, w celu odzwierciedlenia rzeczywistych właściwości analizowanego materiału [20-22].

Jednym z głównych i najczęściej stosowanych modeli homogenizacji analitycznej jest model Mori-Tanaka [23], opierający się na rozwiązaniu Eshelby'ego [24]. Główne założenie modelu Mori-Tanaka przedstawia tensor koncentracji odkształceń wszystkich wtrąceń jako tensor koncentracji odkształcenia dla pojedynczego wtrącenia:

$$
B^{\varepsilon}=H^{\varepsilon}\left(I, C_{0}, C_{1}\right)
$$

gdzie: $B^{\varepsilon}$ - tensor koncentracji odkształceń wszystkich wtrąceń,

$H^{\varepsilon}$ - tensor koncentracji odkształcenia dla pojedynczego wtrącenia,

$C_{0}$ - sztywność matrycy,

$C_{1}$ - sztywność wtrącenia,

$I-$ wtrącenie.

Należy wspomnieć, że model Mori-Tanaka jest efektywny w prognozowaniu właściwości kompozytów dwufazowych o liczbie wtrąceń do $25 \%$, a nawet i wyższych wartości. Analizowany obszar materiału interpretuje się jako nieskończony oraz przyjmuje się, że średnie odkształcenia matrycy i wtrącenia w analizowanym reprezentatywnym elemencie objętościowym mogą być interpretowane jako odkształcenia dla całego obszaru występowania matrycy w skali makroskopowej [25-26].

Celem niniejszej pracy była ocena efektywności zastosowania modeli mikromechanicznych Folgara-Tuckera oraz RSC w prognozowaniu powtryskowej orientacji włókien w matrycy polimerowej dla kompozytu WPC zawierającego $15 \%$ mas. włókien drzewnych. Ponadto otrzymane wartości tensora orientacji włókien w matrycy polimerowej pozwoliły na ocenę wpływu zastosowanych modeli mikromechanicznych na możliwości prognozowania właściwości mechanicznych kompozytu WPC z zastosowaniem modelu homogenizacji Mori-Tanaka. Należy zauważyć, że domyślnym modelem mikromechanicznym stosowanym w wielu programach CAE z zakresu technologii formowania wtryskowego jest model Folgara-Tuckera. Istotne staje się zadanie oceny opcjonalnego modelu RSC w zastosowaniach związanych z prognozowaniem właściwości przetwórczych i mechanicznych kompozytów WPC.

\section{Formowanie wtryskowe kompozytu WPC - eksperyment i analiza numeryczna procesu}

W celu wytworzenia kompozytu WPC jako matrycę polimerową zastosowano polipropylen o nazwie handlowej Moplen HP 648T. Jako napełniacz zastosowano włókna drzewne o nazwie handlowej Lignocel C120 o długości ok. $1 \mathrm{~mm}$ oraz stosunku długości $l$ do średnicy $d$ włókien wynoszącym 10. Ponadto do 
wytworzenia kompozytu użyto promotora adhezyjnego Fusabond P613 o wskaźniku szybkości płynięcia MFR (ang. Melt Flow Rate) wynoszącym 49 g/10 min. Udział napełniacza w matrycy polimerowej to $15 \%$ mas. Kompozyt wytworzono z użyciem wytłaczarki jednoślimakowej EHP 25 firmy ZAMAK. Kształtki o geometrii wiosełek wtryskiwano z użyciem wtryskarki Dr. Boy 55E. W celu otrzymania wiosełek z kompozytu WPC o właściwych parametrach kształtowo-wymiarowych zastosowano parametry nastawne przedstawione w tab. 1. Otrzymane próbki (w celu przeprowadzenia analizy statystycznej wytworzono 7 sztuk) z kompozytu WPC poddano próbie jednoosiowego rozciągania na maszynie wytrzymałościowej Zwick Z030 zgodnie z normą ISO 527-1.

Tabela 1. Parametry nastawne procesu formowania wtryskowego kształtek do próby jednoosiowego rozciągania

Table 1. The processing parameters of the injection molding process for uniaxial tensile test samples

\begin{tabular}{|l|c|}
\hline \multicolumn{1}{|c|}{ Parametr } & Wartość \\
\hline Temperatura formy, ${ }^{\circ} \mathrm{C}$ & 40 \\
\hline Temperatura tworzywa, ${ }^{\circ} \mathrm{C}$ & 190 \\
\hline Natężenie przepływu, $\mathrm{cm}^{3} / \mathrm{s}$ & 20 \\
\hline Czas chłodzenia, $\mathrm{s}$ & 35 \\
\hline Czas docisku, $\mathrm{s}$ & 20 \\
\hline Ciśnienie docisku, $\mathrm{MPa}$ & 30 \\
\hline
\end{tabular}

Symulację procesu formowania wtryskowego przeprowadzono z użyciem oprogramowania Autodesk Moldflow Insight ver. 2016 dla tożsamych parametrów nastawnych procesu wtryskiwania jak w badaniach eksperymentalnych (tab. 1.). Ponadto w celu wykonania poprawnej analizy wprowadzono do programu dane dotyczące właściwości mechanicznych i przetwórczych matrycy polimerowej i włókien. Model numeryczny wtryskiwanego wiosełka przeznaczonego do próby jednoosiowego rozciągania został zdyskretyzowany z użyciem ok. 100 tys. ES typu tetra. Przeprowadzono dwie symulacje wtryskiwania kompozytu WPC, gdzie zmiennym elementem w algorytmie obliczeniowym programu było zastosowanie modeli prognozujących orientację włókien w matrycy polimerowej. Były to modele mikromechaniczne: Folgara-Tuckera oraz RSC. Dla przeprowadzonych symulacji zbadano wartości składowe tensora orientacji włókien w części pomiarowej próbki przeznaczonej do jednoosiowego rozciągania. Odnotowano odmienne wartości dla obu analiz (tab. 2.). Widoczne jest otrzymanie wyższych wartości tensora orientacji włókien $a_{11}$ wzdłuż kierunku przepływu dla modelu Folgara-Tuckera, co jest potwierdzeniem informacji przedstawianych w literaturze. Otrzymane wyniki zostały wykorzystane jako dane wejściowe do obliczeń związanych z prognozowaniem właściwości kompozytów WPC z wykorzystaniem modelu homogenizacji Mori-Tanaka. 
Tabela 2. Obliczone wartości tensora orientacji włókien dla stosowanych modeli mikromechanicznych

Table 2. The obtained values of fiber orientation tensor for the applied micromechanical models

\begin{tabular}{|l|c|c|c|}
\hline \multirow{2}{*}{ Model mikromechaniczny } & \multicolumn{3}{|c|}{ Składowe tensora orientacji włókien } \\
\cline { 2 - 4 } & $a_{11}$ & $a_{22}$ & $a_{33}$ \\
\hline Folgara-Tuckera & 0,7371 & 0,1745 & 0,0884 \\
\hline RSC & 0,7274 & 0,1802 & 0,0924 \\
\hline
\end{tabular}

Zbadano również wizualnie za pomocą mikroskopu orientację włókien na warstwie wierzchniej wypraski w części chwytowej wiosełka (rys. 1.) dla symulacji i eksperymentu. Zauważono dużą zgodność z eksperymentem rozmieszczenia włókien w matrycy polimerowej dla analizy, w której wykorzystano model RSC. W wynikach tej analizy widoczne są: zjawisko dezorientacji włókien przy krawędziach części chwytowej wiosełka oraz wysoka jednokierunkowość włókien w rdzeniu części chwytowej (rys. 1b, c). Jest to bardzo istotny fakt, gdyż rozmieszczenie włókien w matrycy polimerowej istotnie warunkuje właściwości mechaniczne otrzymanych kompozytów.

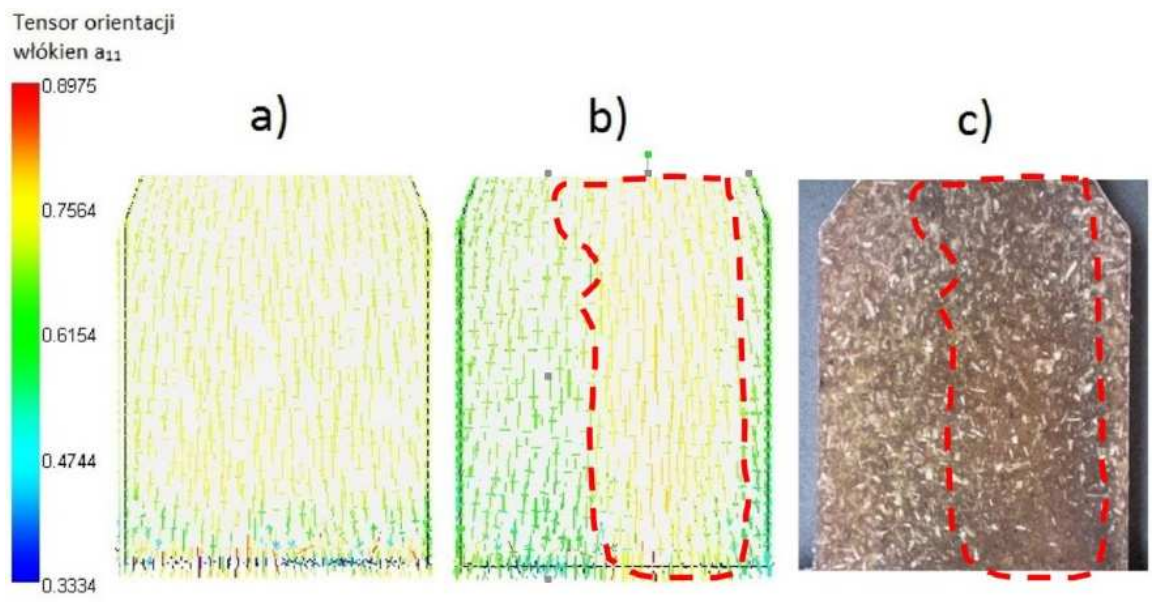

Rys. 1. Orientacja włókien na warstwie wierzchniej wypraski w części chwytowej wiosełka: a) z wykorzystaniem modelu Folgara-Tuckera, b) z wykorzystaniem modelu RSC, c) obraz próbki wykonany za pomocą mikroskopu

Fig. 1. Orientation of fibers on the surface layer of the sample in the grip part: a) using the Folgar-Tucker model, b) using the RSC model, c) microscopic image 


\section{Prognozowanie właściwości mechanicznych kompozytu}

Prognozowanie właściwości mechanicznych kompozytu WPC przeprowadzono z użyciem oprogramowania DIGIMAT MF ver. 2016. Program ten pozwala na uzyskanie danych dotyczących właściwości mechanicznych materiałów kompozytowych, korzystając w swym algorytmie obliczeniowym z modelu homogenizacji Mori-Tanaka i uwzględniając rzeczywistą, powtryskową orientację włókien w matrycy polimerowej. Wartości składowych tensora orientacji włókien $\left(a_{11}, a_{22}, a_{33}\right)$ obliczone z wykorzystaniem modeli mikromechanicznych Folgara-Tuckera oraz RSC (tab. 2.) wprowadzono jako dane wstępne do przeprowadzenia analizy mikromechanicznej. Ponadto zdefiniowano dane dotyczące właściwości mechanicznych i fizycznych włókien i osnowy, w tym m.in.: moduł Younga, współczynnik Poissona, granicę plastyczności, gęstość, stosunek długości do średnicy włókna $(l / d)$ oraz zawartość masową napełniacza w matrycy polimerowej.

Tabela 3. Macierze sztywności obliczone dla kompozytów z danymi dotyczącymi orientacji włókien z modelu: a) Folgara-Tuckera, b) RSC

Table 3. Stiffness matrices calculated for composites with the data on fiber orientation from the model: a) Folgar-Tucker, b) RSC

a)

\begin{tabular}{|c|c|c|c|c|c|}
\hline 3692,5 & 2247,1 & 2227,3 & 0 & 0 & 0 \\
\hline 2247,1 & 3484,5 & 2209,2 & 0 & 0 & 0 \\
\hline 2227,3 & 2209,2 & 3469,7 & 0 & 0 & 0 \\
\hline 0 & 0 & 0 & 621,34 & 0 & 0 \\
\hline 0 & 0 & 0 & 0 & 631,83 & 0 \\
\hline 0 & 0 & 0 & 0 & 0 & 607,99 \\
\hline
\end{tabular}

b)

\begin{tabular}{|c|c|c|c|c|c|}
\hline 3687,1 & 2247,9 & 2228 & 0 & 0 & 0 \\
\hline 2247,9 & 3485,3 & 2209,9 & 0 & 0 & 0 \\
\hline 2228 & 2209,9 & 3469,9 & 0 & 0 & 0 \\
\hline 0 & 0 & 0 & 622,42 & 0 & 0 \\
\hline 0 & 0 & 0 & 0 & 631,78 & 0 \\
\hline 0 & 0 & 0 & 0 & 0 & 609,09 \\
\hline
\end{tabular}

Przeprowadzono dwie analizy dla zmiennych wartości składowych tensora orientacji włókien. Jednym kryterium wynikowym były macierze sztywności. Jak widać (tab. 3.), otrzymano zmienne wartości składowych macierzy sztywności dla dwóch przeprowadzonych analiz. Ponadto otrzymano dane dotyczące właściwości kompozytu w zakresie sprężystym (tab. 4.). Analizując otrzymane wartości modułu Younga, na kierunku wzdłużnym E1 odnotowano niższe wartości dla analizy, gdzie wartości składowe tensora orientacji włókien uzyskano z obliczeń 
opierających się na modelu RSC. Odnosząc się do wartości modułu Younga wynoszącej ok. $1720 \mathrm{MPa}$, otrzymanej eksperymentalnie z próby jednoosiowego rozciągania, wyniki dla modelu RSC odbiegają o ok. 12\% od wartości rzeczywistych. W odniesieniu do obliczonych charakterystyk naprężenie-odkształcenie (rys. 2.) dla zmiennych modeli mikromechanicznych można zauważyć dość dużą zgodność z eksperymentem dla stosowanych wartości składowych tensora orientacji włókien otrzymanych z obu analiz.

Tabela 4. Obliczone właściwości mechaniczne (w zakresie sprężystym) dla zmiennych wartości składowych tensora orientacji włókien

Table 4. Calculated mechanical properties (in elastic range) for variable values of fiber orientation tensor components

\begin{tabular}{|l|c|c|}
\hline \multicolumn{1}{|c|}{ Parametr } & Folgar-Tucker & RSC \\
\hline Gęstość, kg/m ${ }^{3}$ & 1034 & 1034 \\
\hline Moduł Younga E1, MPa & 1931,9 & 1925,8 \\
\hline Moduł Younga E2, MPa & 1774,2 & 1773,4 \\
\hline Moduł Younga E3, MPa & 1781,8 & 1780,7 \\
\hline Współczynnik Poissona v12 & 0,39893 & 0,39892 \\
\hline Współczynnik Poissona v21 & 0,36635 & 0,36735 \\
\hline Współczynnik Poissona v13 & 0,38794 & 0,38803 \\
\hline Współczynnik Poissona v31 & 0,35779 & 0,35879 \\
\hline Współczynnik Poissona v23 & 0,40155 & 0,401 \\
\hline Współczynnik Poissona v32 & 0,40328 & 0,40266 \\
\hline Moduł Kirchhoffa G12, MPa & 621,34 & 622,42 \\
\hline Moduł Kirchhoffa G23, MPa & 607,99 & 609,09 \\
\hline Moduł Kirchhoffa G13, MPa & 631,83 & 631,78 \\
\hline
\end{tabular}

\section{Podsumowanie}

Wybór modelu mikromechanicznego w obliczeniach dotyczących prognozowania orientacji włókien w matrycy polimerowej kompozytu WPC wpływa na wartości składowe tensora orientacji włókien. Większe wartości tensora orientacji włókien $a_{11}$ uzyskano (wzdłuż kierunku przepływu tworzywa) dla modelu Folgara-Tuckera. Potwierdzają to informacje zawarte w literaturze, w których model Folgara-Tuckera często zawyża wyniki dotyczące wartości składowych tensora orientacji włókien w porównaniu z modelem RSC.

Odnotowano dużą zgodność z eksperymentem w kontekście rozmieszczenia włókien w matrycy polimerowej dla analizy z wykorzystaniem modelu RSC. $\mathrm{W}$ tym celu zbadano organoleptycznie orientację włókien na warstwie wierzchniej wypraski w części chwytowej próbki do jednoosiowego rozciągania. Na podstawie takiej analizy można stwierdzić, że model RSC pozwala na realne odzwierciedlenie zachowania tworzywa $\mathrm{z}$ włóknem w trakcie wypełnienia gniazda formującego. 


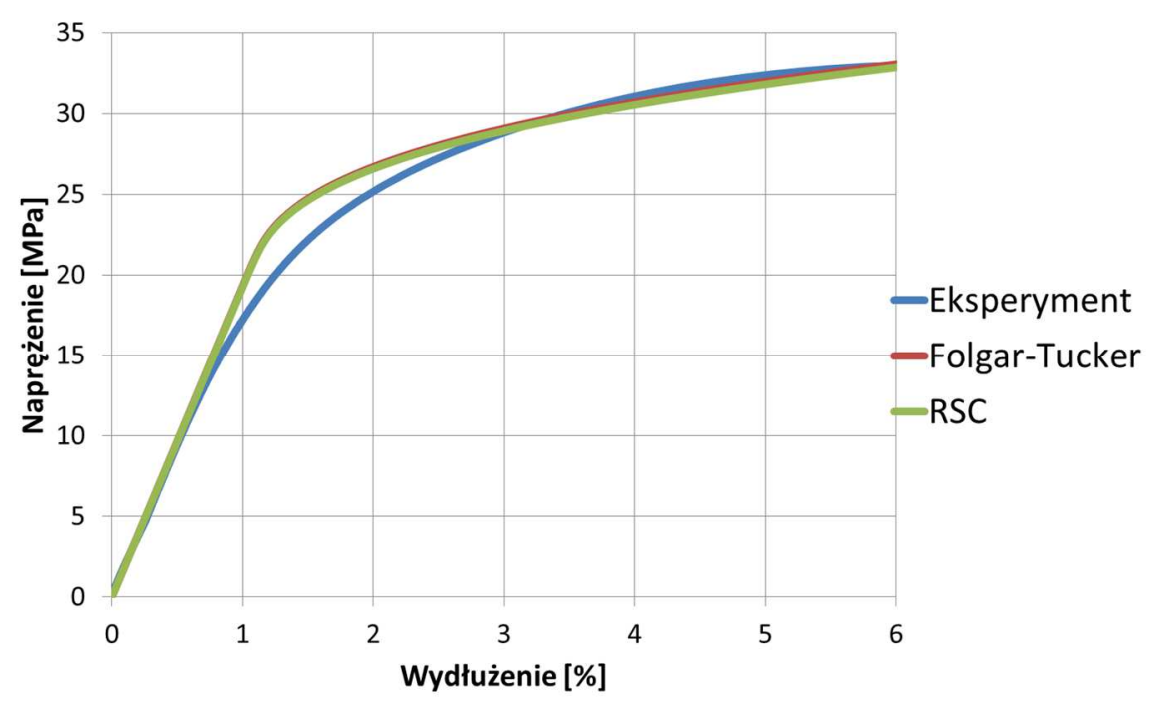

Rys. 2. Otrzymane charakterystyki naprężenie-wydłużenie dla kompozytu WPC z analiz numerycznych i eksperymentu

Fig. 2. The obtained stress-elongation characteristics for WPC composite from numerical analyzes and the experiment

Dzięki obliczonym i potwierdzonym eksperymentalnie wartościom składowym tensora orientacji włókien w dużym stopniu możliwe było przeprowadzenie obliczeń dotyczących prognozowania właściwości mechanicznych z uwzględnieniem powtryskowej orientacji włókien w matrycy polimerowej przy użyciu modelu homogenizacji Mori-Tanaka. Otrzymano dość dużą zgodność z eksperymentem w przypadku badanych charakterystyk naprężenie-odkształcenie oraz wartości modułu Younga dla wprowadzonych wartości składowych tensora orientacji włókien z wykorzystaniem zarówno modelu RSC, jak i Folgara-Tuckera.

\section{Literatura}

[1] Klyosov A.A.: Wood-plastic composites, Wiley, New Jersey 2007.

[2] Kaczmar J.W., Pach J.: Kompozyty polimerowe wzmacniane włóknami naturalnymi, Tworzywa Sztuczne i Chemia, 4 (2007) 14-16.

[3] Ziąbka M., Szaraniec B.: Kompozyty polimerowe z dodatkiem włókien naturalnych, Kompozyty, 10 (2010) 138-142.

[4] Wechsler A., Hiziroglu S.: Some of the properties of wood-plastic composites, Building Environment, 42 (2007) 2637-2644.

[5] Frącz W., Janowski G.: Zaawansowana analiza wytrzymałościowa wypraski z kompozytu WPC z uwzględnieniem powtryskowej orientacji włókien w osnowie polimerowej, Mechanik, 7 (2016) 628-630. 
[6] Frącz W., Janowski G.: Strength analysis of molded pieces produced from woodpolymer composites (WPC) including their complex structures, Composites Theory Practice, 16 (2016) 260-265.

[7] Jeziorny A.: Skrypty dla szkół wyższych. Nauka o włóknie, Redakcja Wydawnictw Naukowych Politechniki Łódzkiej, Łódź 1980.

[8] Miedzianowska J., Masłowski M., Strzelec K.: Kompozyty polimerowe zawierające włókna roślinne - czynniki wpływające na wytrzymałość mechaniczną, Technologia i Jakość Wyrobów, 63 (2018) 45-54.

[9] Wire S.L.: Fibre Orientation and mechanical properties of fibre reinforced composites. Praca doktorska, University of Leeds, Leeds 1998.

[10] Nabialek J.: Modeling of fiber orientation during injection molding process of polymer composites, Kompozyty, 11 (2011) 347-351.

[11] Jeffery G.B.: The motion of ellipsoidal particles immersed in viscous fluid, Proc. Royal Society London A, 102 (1922) 161-179.

[12] Dinh S.M., Armstrong R.C.: A rheological equation of state for semi-concentrated fiber suspensions, J. Rheology, 28 (1984) 207-227.

[13] Folgar F., Tucker C.L.: Orientation behavior of fibers in concentrated suspensions, J. Reinforced Plastics Composites, 3 (1984) 98-119.

[14] Wang J., O'Gara J.F., Tucker III C.L.: An objective model for slow orientation kinetics in concentrated fiber suspensions: Theory and rheological evidence, J. Rheology, 52 (2008) 1179-1200.

[15] Tucker III C.L., Wang J., O'Gara J.F.: Method and Article of Manufacture for Determining a Rate of Change of Orientation of a Plurality of Fibers Disposed in a Fluid, US Patent US7266469B1, 2007.

[16] Buck F., Brylka B., Müller V., Müller T., Hrymak A.N., Henning F., Böhlke T.: Coupling of mold flow simulations with two-scale structural mechanical simulations for long fiber reinforced thermoplastics, Mater. Sci. Forum, 825 (2015) 655-662.

[17] Kleindel S., Salaberger D., Eder R., Schretter H., Hochenauer C.: Prediction and validation of short fiber orientation in a complex injection molded part with chunky geometry, Int. Polymer Processing, 30 (2015) 366-380.

[18] Pomoc programu Autodesk Moldflow Insight 2016.

[19] Meyer K.J., Hofmann J.T., Baird D.G.: Prediction of short glass fiber orientation in the filling of an end-gated plaque, Composites Part A: Appl. Sci. Manuf., 62 (2014) 77-86.

[20] Amirmaleki M., Samei J., Green D.E., Van Riemsdijk I., Stewart L.: 3D micromechanical modeling of dual phase steels using the representative volume element method, Mech. Materials, 101 (2016) 27-39.

[21] Singh R., Mitra M., Falzon B.G.: Modelling matrix damage and fibre-matrix interfacial decohesion in composite laminates via a multi-fibre multi-layer representative volume element (M2RVE), Int. J. Solids Structures, 51 (2014) 449-461.

[22] Pierard O., LLorca J., Segurado J., Doghri I.: Micromechanics of particle-reinforced elasto-viscoplastic composites: finite element simulations versus affine homogenization, Int. J. Plasticity, 23 (2007) 1041-1060.

[23] Mori T., Tanaka K.: Average stress in matrix and average elastic energy of materials with misfitting inclusions, Acta Metallurgica, 21 (1973) 571-574. 
[24] Eshelby J.D.: The determination of the elastic field of an ellipsoidal inclusion, and related problems, Proceedings of the Royal Society of London A: Math., Physical Eng. Sci., 241 (1957) 376-396.

[25] Ogierman W., Kokot G.: Mean field homogenization in multi-scale modelling of composite materials, J. Achievements Mater. Manuf. Eng., 61 (2013) 343-348.

[26] Benveniste Y.: A new approach to the application of Mori-Tanaka's theory in composite materials, Mech. Materials, 6 (1987) 147-157.

\section{EVALUATION OF THE INFLUENCE OF MICROMECHANICAL MODEL SELECTION ON FORECASTING WPC COMPOSITE FIBER ORIENTATION AND MECHANICAL PROPERTIES}

\section{S u m m a r y}

This article evaluates the effectiveness of selected micromechanical models, such as FolgarTucker and RSC, in numerical calculations concerning fiber orientation prediction in a polymer matrix for the WPC composite containing $15 \%$ by mass of wood fibers. In addition, the obtained values of fiber orientation tensor in the polymer matrix allowed to assess the influence of the applied micromechanical models on the possibilities of predicting the mechanical properties of the WPC composite using the Mori-Tanaka homogenization model. It should be noted that the default micromechanical model suggested in CAE software including the injection moulding process modules is the Folgar-Tucker model. Hence, it is important to investigate whether the second optional model, i.e. RSC, should be the main model used in predicting the processing and mechanical properties of WPC composites.

Keywords: WPC composites, fibers orientation, micromechanical models, injection molding, homogenization models

DOI: $10.7862 / \mathrm{rm} .2019 .01$

Otrzymano/received: $12.06 .2019 \mathrm{r}$.

Zaakceptowano/accepted: 14.07.2019 r. 